\title{
Foro: Balance y perspectivas de la modernización del sector salud
}

\author{
INTERVENCIÓN DE: \\ David Tejada de Rivero \\ Miembro del Consejo Consultivo del Ministerio de Salud
}

E

1 tema de este foro es "Balance y perspectivas de la modernización del sector salud". Pero, ¿tenemos un concepto único de lo que es salud y de lo que es sector?, ¿es el sector lo más conveniente como sujeto de análisis?, ¿a qué se llama modernización hoy en día?, ¿estamos todos de acuerdo?, ¿qué elementos se requiere para hacer un balance?, ¿es adecuado el término perspectivas o, tal vez, es mejor referirse a prospectiva? Ante estas interrogantes, he circunscrito mi presentación para poder contribuir con un marco de referencia, porque puede ocurrirnos lo que hoy los franceses están llamando el síndrome de la babelización: viejos conceptos con nuevos nombres, o viejos nombres con nuevos conceptos, $\mathrm{y}$ cada cual interpretado de un modo muy particular; lo cual parece una contradicción en un mundo que se dice ser una sociedad de la comunicación. En realidad, se trata de monólogos donde todos pueden tener la razón, porque no se refieren a lo mismo.

\section{Necesidad de algunas definiciones conceptuales para la delimitación y comprensión del tema}

Es necesario referirnos a algunas definiciones conceptuales para la delimitación y comprensión del tema. A continuación examinaremos los términos que están contenidos en el título de este foro.

¿Qué es balance?

El balance debe ser entendido como el estudio comparativo de los hechos favorables y desfavorables de una situación no estamos hablando de balance en términos comerciales-. El balance requiere, exige, parámetros de comparación, ya que se trata de un enjuiciamiento que está determinado en última instancia por valores, y hoy en día los valores que están reemergiendo como fundamentales, para cualquier balance, son los éticos y morales. 


\section{¿Qué es perspectiva?}

La perspectiva puede entenderse como el modo de representar en una superficie los objetos en la forma y disposición espacial con que aparecen a la vista. Esa es la definición. Aunque pueda aparecer como algo contradictorio, la perspectiva siempre es retrospectiva, porque es la proyección en función de lo que hay y de lo que ha sido. Tal vez, en nuestro caso, el término más exacto sería prospectiva, en el sentido de un conjunto de análisis y estudios realizados con el fin de explorar y predecir el futuro en una determinada materia. La prospectiva no viene del pasado, sino de un futuro deseado y posible y, por tanto, puede requerir categorías de análisis no existentes en el presente -considerando, además, que el presente es siempre ya pasado-. Se supone que este es el propósito de este foro; es decir, una prospectiva.

\section{¿Qué es modernización?}

La modernización puede entenderse como la acción y el efecto de modernizar o modernizarse; a su vez, modernizar se entiende como hacer que alguien o algo pase a ser moderno, mientras moderno significa aquello perteneciente al tiempo en que se vive, al tiempo en que se habla o a una época reciente. En cuanto a la palabra modernismo, esta tiene tres principales acepciones, aunque no se aplican al presente tema: la afición a las cosas modernas con menosprecio de las antiguas, especialmente en el arte y la literatura; el movimiento religioso de fines del siglo XIX y comienzos del XX; y el movimiento literario también de finales del siglo XIX y principios del XX. Por último, modernidad significa cualidad de moderno. Hoy, de una forma convencional, principalmente en Europa y Estados Unidos de América, se acepta que modernización debe referirse al uso de lo más moderno en ciencia y tecnología, mientras que modernidad se relaciona con la adecuación de una sociedad a los tiempos presentes y a lo que pasa en el mundo. Además hay una corriente de pensamiento que indica que la verdadera modernidad tiene que ver con el desarrollo del género humano y su humanización y, por lo tanto, con su alejamiento de lo animal y lo primitivo; finalmente, no dejan de haber otros que dan este mismo sentido a la modernización. Frente al tema que nos ocupa, creemos que el sentido de modernización debe ligarse al concepto de modernidad como alejamiento de la animalidad y de lo primitivo, es decir, como un volverse el hombre más humano en el sentido profundamente filosófico y moral.

¿Qué es salud?

¿A qué salud nos estamos refiriendo? A una realidad social muy compleja donde se dan simultánea, sinérgica y antagónicamente, muchos procesos sociales que constituyen y, a la vez, condicionan y determinan, en diferentes grados y sentidos, los factores que favorecen o perjudican el ciclo vital de un ser humano. La salud lleva implícito el sentido de una meta, de una meta relativa a una vida prolongada y con la eliminación máxima posible de riesgos y accidentes negativos. Cabe mencionar que esos factores causales, condicionantes y determinantes vienen de, por lo menos, dos generaciones anteriores a la concepción del huevo y el embrión, son pues procesos y factores genéticos, ecológicos, ambientales, culturales, sociales, 
económicos y políticos; de ahí la tremenda complejidad de esta y otras realidades sociales.

También podemos entender la salud como parte integrante de un estado o situación de bienestar y desarrollo en el cual el propósito o fin central es la persona humana en su sentido individual $\mathrm{y}$, a la vez, más plural, sin excepciones, exclusiones, marginaciones ni discriminaciones. Lo último obedece a un determinado marco de valores éticos y morales; por ejemplo, "Salud para todos" fue siempre-y yo estuve muy envuelto en el origen de esto- una meta social derivada de los valores éticos y morales de la cultura llamada occidental cristiana. Nunca fue una meta técnica ni mucho menos solamente programática.

Derivado de lo anterior, la salud pasa a ser también parte fundamental de un conjunto de valores éticos y morales que la elevan, en forma natural, a ser un derecho humano inalienable y reconocido $\mathrm{y}$, por lo tanto, aceptado universalmente, aunque a veces sea solamente en forma declarativa.

Como complemento de lo anterior lo que generalmente es obviado y olvidado-, la salud debe entenderse como un deber y una responsabilidad social, es decir, de la sociedad y de sus estructuras sociales formales de acción, como el Estado; de las formas elementales de la sociedad, desde donde nace la soberanía ciudadana que formaliza y legitima el Estado, y también de otras instituciones sociales. El individuo, la familia, la comunidad, la sociedad civil, las organizaciones sociales emergentes de base, etc., no dejan de tener este deber y responsabilidad, ni el Estado puede renunciar a su importante papel de cumplir y hacer cumplir este deber y responsabilidad.

La salud también puede ser entendida como parte, fin y medio -o en el lenguaje economicista, producto e insumo- del proceso económico, pero entendiendo este como un esfuerzo colectivo para satisfacer las necesidades de un desarrollo humano y no sólo circunscrito al crecimiento de algunas variables macroeconómicas. Esta concepción determina la diferencia de enfoque y de interpretación de la respuesta social a los problemas de salud; es decir, la diferencia entre gasto e inversión social.

La salud también puede ser considerada como un proceso político al cual afectan, en forma positiva, negativa o perversa, las decisiones políticas en todos los ámbitos del quehacer social -entendido este en su verdadero sentido, que involucra lo económico, lo jurídico, etc.-. La esfera de las decisiones políticas comprende desde la priorización de las necesidades, demanda y problemas hasta los enfoques y formas de enfrentarlos.

¿Qué es sector?

Entendemos sector como una parte arbitraria y convencionalmente definida y delimitada de las grandes áreas de la acción social $\mathrm{y}$, principalmente, integradas por instituciones formales y burocráticas -no en el sentido peyorativo de la palabra-. Se entiende que esta delimitación es neta y sin residuos, pero sector tiene, inevitablemente, una connotación geométrica que contribuye muy negativamente a la conceptualización de la salud, ya que es una porción del círculo comprendida entre un arco y los dos ra- 
dios que pasan por sus extremidades; precisamente, ello hace suponer delimitaciones nítidas sin traslapes ni áreas comunes a varios sectores.

Por esta razón, en el tema de la salud sería mejor hablar de ámbito, entendido como el espacio ideal configurado por las cuestiones y los problemas de una o varias actividades o disciplinas relacionadas entre sí. Los ámbitos se traslapan, envuelven a otros y a todos, y son envueltos por otros y por todos; todo a la vez. Así son las realidades sociales. Por ello, los ámbitos deben definirse y delimitarse reconociendo que sus límites nunca serán netos ni contendrán el todo de un problema o cuestión. Toda definición y delimitación dependerá de los propósitos, puntos de partida-aquí sí se emplea correctamente perspectivas- y, sobre todo, de las prospectivas condicionadas por valores éticos y morales.

\section{Herramientas de medición y comparación necesarias para juicios valorativos}

El segundo punto al que me voy a referir son las herramientas de medición y comparación necesarias para juicios valorativos, como los balances. Si decimos que el modelo de salud está bien, que las reformas de salud están dando resultados, ¿qué herramientas tenemos para poder hacer esos juicios de valor?

\section{Las dos caras de la salud}

En un peligroso esfuerzo de simplificación, pero necesario para nuestros fines prácticos, la salud puede ser vista como un asunto de dos caras complementarias, pero no iguales ni del mismo valor. Una debe condicionar a la otra y no viceversa. La cara fundamental es la cara de las necesidades, algunas no percibidas, otras percibidas, algunas sentidas y otras que se convierten en exigencias; es la cara de las demandas -lo que constituye un paso adelante de las necesidades-, tanto de las no políticas como de las políticas, que exigen a los niveles de decisión acciones y recursos; es la cara de los problemas determinados por necesidades no satisfechas y que adquieren características de algo negativo que debe enfrentarse y resolverse de alguna manera. Un problema se genera, precisamente, cuando una necesidad se convierte en demanda política tan exigente que obliga a ser considerada porque implica una situación negativa, desfavorable o perversa. En el lenguaje economicista, esta cara es la demanda, pero en un sentido de mercado, y no necesariamente de derecho humano.

El modelo flexneriano, que a pesar de su crisis irreversible es aún predominante y hegemónico en el mundo, ha olvidado sistemáticamente esta cara de la demanda, que es la más importante y que condiciona a la otra -y respondo acá a la pregunta del señor decano de ESAN acerca de cuál modelo está en vigencia y cuál es su validez-. Este modelo se llama así por los hermanos Flexner, quienes hicieron su planteamiento sobre la salud a fines de la década de los 20 y a comienzos de la década de los 30; esto es, entre $70 \mathrm{y}$ 80 años atrás. Todos los documentos de análisis, todos los documentos de reforma de la salud se refieren solo a la otra cara, a la cara llamada de la oferta en el lenguaje economicista.

La cara de la oferta es complementaria, pero secundaria, dependiente; es la cara 
de las respuestas de la sociedad a las necesidades y a los problemas. Y cuando digo que es oferta en el lenguaje economicista, digo economicista entre comillas, porque me refiero a ese prurito de pensar en términos económicos donde corresponde y donde no corresponde.

En la práctica ideológica de la salud, la cara de la oferta se circunscribe, peligrosamente, al sistema o aparato institucional o sectorial de servicios de atención, mayormente, reparativa. Es la cara única a la que el modelo flexneriano se ha circunscrito, es la cara única a la que por deformación profesional nos hemos acostumbrado. Olvidamos que esta cara no es sino una respuesta a lo que indica $u$ orienta la cara principal. A esta cara se han reducido los esfuerzos de las llamadas reformas y también de una llamada modernización, que no corresponde a la modernidad que requiere el mundo de hoy.

Marcos de referencia y categorías de análisis

El balance y la apreciación prospectiva de una situación determinada, como la del tema actual, requieren de una marco de referencia y, derivado de este, de un conjunto de categorías de análisis. En otras palabras, no podemos seguir trabajando con categorías de análisis del modelo flexneriano.

El marco de referencia tiene esencialmente un carácter valorativo, en este los valores éticos y morales -y también, hasta hace muy poco, los valores no éticos, inmorales y amorales, convertidos prácticamente en una emergente nueva religión o nueva filosofía social- dan contenido y sentido a los objetos y sujetos de análisis. No estoy pronunciándome en contra de ciertas ideas, sino simplemente enunciando desde mi perspectiva de pertenecer a un ámbito de pensamiento de civilización occidental cristiana.

Por lo tanto, las categorías de análisis no son jamás solo técnicas, no son neutras ideológicamente, no son independientes de los valores del marco de referencia. La información necesaria para un balance debe corresponder, entonces, a las categorías de análisis que sean pertinentes, no a las viejas categorías de análisis.

Finalmente, en un balance prospectivo, es indispensable la consideración de lo que se supone ocurriría más probablemente en el futuro. No podemos tratar del tema de la salud sin una idea clara del tipo de sociedad a la que nosotros queremos llegar. ¿Queremos llegar a una sociedad injusta, una sociedad primitiva donde la ley del más fuerte predomine, o queremos llegar a una sociedad justa, una sociedad participativa, una sociedad democrática sin desigualdades, sin exclusiones, sin marginaciones? Tenemos que hacer esta elección.

\section{Cuidado integral de la salud}

Paso ahora al cuidado integral de la salud -y estoy empleando los términos muy cuidadosamente-. Los términos "cuidado integral de la salud" son más adecuados que los términos "atención de la salud", pues en la práctica la "atención de salud" se reduce a "atención médica", y esta, a su vez, es mayormente "atención médico reparativa”. Esta es consecuencia, una vez más, del modelo flexneriano, que ha hecho identificar falsamente "salud" con "enfermedad", "salud" con "medicina" y 
"médicos", "salud" con "servicios de atención médica" y, finalmente, estos últimos como el "todo" del sistema de oferta. Como ese "todo" no considera la cara más importante de la salud, los sistemas tienden a ser -como reflejo de la sociedad prevalente- burocratizados, centralistas, autocráticos, no participativos. ¿Queremos continuar con un modelo de ese tipo o no? Este es el tema del debate.

Por el contrario, el término "cuidado integral de la salud" supone considerar que la salud debe ser vista no sólo desde la perspectiva de la oferta institucional de la atención, sino, fundamentalmente, de las necesidades, demandas y problemas de salud, considerando el derecho de todos a un nivel digno de salud y a que no existan insultantes diferencias e injusticias tanto en los niveles de salud, medidos de cualquier manera, como en la asignación de los recursos que la sociedad da para ese cuidado integral.

El sentido de integral se refiere también a que la respuesta social es inevitablemente multisectorial; esta respuesta no es integral porque están todos los aspectos clásicos de la atención médica, es integral porque es, inevitablemente, multisectorial y orientada a las causas profundas $\mathrm{y}$, muchas veces, no visibles que afectan la salud de todos: empleo, ingreso digno, disponibilidad de alimentos, educación, agua segura, ambiente sin contaminación, libertades, oportunidades reales para la realización de todos, etc. Esos son elementos que corresponden al cuidado integral de la salud. Al cuidado integral de la salud corresponde la necesidad de políticas públicas del Estado, sin circunscribirse sólo a políticas de salud, sectoriales $\mathrm{y}$, mucho menos, institucionales.
Por todo lo anterior, es posible que, para un balance prospectivo de la salud y para medir si efectivamente se ha modernizado el sistema, la información actual disponible no sea la pertinente y que la información fundamental no sea utilizada porque no se considera que sea relativa a la salud, aunque lo sea para el restringido y negativo sentido del sector institucional de atención.

\section{Necesidad de un nuevo modelo de salud para elaborar los marcos de referencia y las categorías de análisis que permi- tan un balance}

\section{Un análisis histórico imprescindible}

El modelo hegemónico llamado "flexneriano", que considera la salud circunscrita a la atención médica -mayormente reparativa- "entregada" o "prestadada" por un sistema de oferta institucionalizado, burocrático, centralista y autoritario, es la consecuencia de una decisión de una institución filantrópica de los Estados Unidos de América, la Fundación Rockefeller, después de un debate histórico llevado a cabo a fines de la década de los 20 y comienzos de la década de los 30. Ese debate fue el enfrentamiento entre dos escuelas muy diferentes de pensamiento: por un lado, los hermanos Flexner: Simon y Abraham, bajo la sombra de John Dewey, de John Hopkins -el gran reformador de la educación en aquella época y hoy considerado el gran deformador de la educación que se necesita para el mundo actual-, y por otro lado la escuela de Roseanau de Harvard.

La decisión de la Rockfeller Foundation estuvo influenciada por John Dewey y los hermanos Flexner - uno educador y el otro 
microbiólogo, quien veía los problemas con microscopio, no percibía los contextos-, directivo y funcionarios, respectivamente, de la Fundación. El modelo se impuso, casi simultáneamente, en todo el mundo, principalmente a través de las universidades y las escuelas de salud pública sembradas en el mundo con el modelo de Hopkins. Yo he visto en Calcuta, en Alejandría, en México y en muchos otros lugares del mundo, escuelas de salud pública construidas con los mismos planos de los edificios de la Escuela de Salud Pública de John Hopkins, en Baltimore.

\section{La crisis irreversible del modelo flexneriano}

En la crisis del modelo flexneriano hubo diversos factores, pero el decisivo, aunque no el más importante socialmente en un mundo tan economicista como el de hoy, fue el impacto de la agresiva e incontrolada comercialización de la aplicación al campo del diagnóstico de ciertas enfermedades, de los avances de la ciencia y la tecnología hechos a partir del inicio de la guerra fría, en la segunda mitad de la década de los 40. Ello ha determinado un crecimiento exponencial de los costos de la atención médica, los que ninguna sociedad nacional, ni siquiera los Estados Unidos de América, es capaz hoy día de absorber.
El precio que se paga es, entre otros hechos, la reducción de las coberturas, con abandono y exclusión, en la práctica, de los grupos poblacionales más necesitados y en mayor riesgo, principalmente, y el deterioro de las remuneraciones de los recursos humanos del sistema institucional formal de oferta.

Pero el mayor daño provocado por el modelo flexneriano es la apropiación que el sistema formal institucionalizado ha hecho de los derechos y deberes de la ciudadanía, personas y comunidades, con respecto al cuidado integral de su salud. Nunca las personas debieron llamarse pacientes, término que significa ser pasivos, no responsables, no capaces de reclamar sus derechos ni de ejercer sus deberes. De ahí que cuando se habla de recursos humanos, por ejemplo, automáticamente se piensa en reducirlos, excluyentemente, a la burocracia -no en sentido peyorativo- del sistema de oferta.

Creo que con esto he tratado de contribuir a que podamos hacer un balance sobre la base de algunos elementos que van más allá de las categorías de análisis tradicionales: morbilidad, mortalidad, números de médicos, proporción de médicos por población, camas utilizadas, entre otros. 